\title{
Evaluation of Sympathetic Activity in Hypertension
}

\author{
${ }^{1}$ Poghni A Peri-Okonny, ${ }^{2}$ Wanpen Vongpatanasin
}

\begin{abstract}
The sympathetic nervous system (SNS) plays a major role in the pathogenesis of hypertension and contributes to hypertensive target organ complications. Advances in technology over the last three decades have improved the ability to measure sympathetic nerve activity (SNA), thus enabling investigators to probe the role of SNS in the development of cardiovascular diseases. The most direct method of measuring SNA employs the technique of microneurography, which involves recording of postganglionic sympathetic action potential using a subcutaneous electrode inserted into the candidate nerve. This method allows assessment of sympathetic vasoconstrictor discharge to the peripheral circulation in hypertension and provides prognostic information in patients with cardiovascular diseases. However, application of microneurography and other methods of assessment of SNS activity, including norepinephrine spillover and imaging of SNS innervation, in routine clinical practice is limited by availability of the technique and lack of normal reference range established from large population-based data. Nevertheless, these measurements provide further insight into mechanisms of hypertension and effectiveness of various interventions in modifying sympathetic regulation of blood pressure.
\end{abstract}

Keywords: Hypertension, Microneurography, Muscle sympathetic nerve activity, Norepinephrine spillover, Renal denervation, Sympathetic nerve activity.

How to cite this article: Peri-Okonny PA, Vongpatanasin W. Evaluation of Sympathetic Activity in Hypertension. Hypertens J 2016;2(2):60-64.

Source of support: Nil

Conflict of interest: None

\section{INTRODUCTION}

The sympathetic branch of the autonomic nervous system plays an important role in regulating the function of different organs over a range of physiologic conditions. ${ }^{1}$ The sympathetic nervous system (SNS) promotes hypertension

\footnotetext{
${ }^{1}$ Fellow, ${ }^{2}$ Professor

${ }^{1}$ Department of Internal Medicine, Hypertension Section University of Texas Southwestern Medical Center, Dallas Texas, USA

${ }^{2}$ Department of Internal Medicine, Hypertension Section Cardiology Division, University of Texas Southwestern Medical Center, Dallas, Texas, USA
}

Corresponding Author: Wanpen Vongpatanasin, Professor Department of Internal Medicine, Hypertension Section Cardiology Division, University of Texas Southwestern Medical Center, Dallas, Texas, USA, Phone: +2146482103 , e-mail: wanpen.vongpatanasin@utsouthwestern.edu by inducing direct vasoconstriction and indirectly via activation of the renin-aldosterone-angiotensin system (RAAS). ${ }^{2}$ In recent years, numerous device-based therapies have been developed to tackle SNS to reduce blood pressure (BP), particularly in patients with resistant hypertension. The effectiveness of these therapies is limited by lack of real-time assessment of sympathetic nerve activity (SNA) during the procedure to determine procedural success. This article provides a brief overview of the different modes of evaluating SNS activity that have been applied in the study of hypertension.

\section{OVERVIEW OF THE SYMPATHETIC PATHWAY}

Afferent signals emanate from visceral organs via the afferent autonomic pathway to the central nervous system where signals are integrated and transmitted through the efferent pathway back to effector organs. Preganglionic efferent fibers have cell bodies in the brain and the intermediolateral horn of the spinal cord at the T1-L2 or L3 levels. The axon terminals of these neurons synapse in vertebral or paravertebral sympathetic ganglia with cell bodies of postganglionic neurons which project to effector organs. Synapses in the sympathetic ganglion use acetylcholine while synapses of postganglion neurons use norepinephrine (NE), with the exception of postsympathetic neurons to the sweat glands which use acetylcholine.

\section{MODES OF SYMPATHETIC NERVE ACTIVITY EVALUATION}

\section{Microneurography}

Microneurography was initially developed by Hagbarth and Vallbo in Upsula, Sweden around 1965 to $1966 .{ }^{3}$ Since then, it has developed into a powerful investigational tool for examining the SNA to muscular and cutaneous vascular beds, both in healthy and diseased states. The technique involves externally mapping the course of a superficial nerve (e.g., peroneal, popliteal, radial, and median) by transcutaneous stimulation to evoke motor or sensory effects. In the case of the commonly used peroneal nerve, the nerve is accessed just under the fibular head with the subject in the supine or seated position. A $200 \mu \mathrm{m}$ tungsten electrode is inserted subcutaneously into the peripheral nerve fascicle to directly record postganglionic efferent sympathetic nerve bursts to the skeletal muscle or skin with a reference electrode positioned within 2 to $3 \mathrm{~cm}$. The raw muscle 


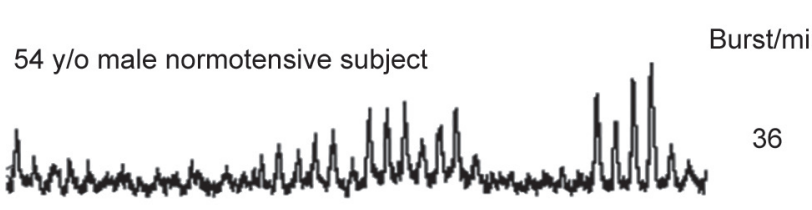

43 y/o male with essential hypertension

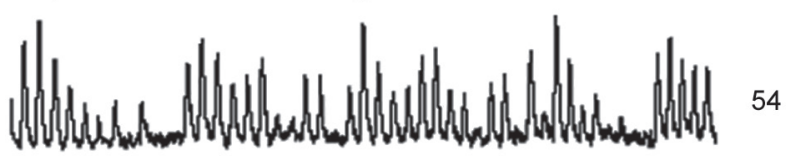

44 y/o subject with primary aldosteronis

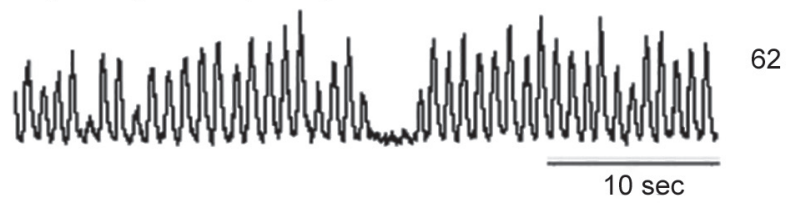

Fig. 1: Representative neurogram

sympathetic nerve activity (MSNA) signal is amplified, filtered, rectified, and integrated to produce a neurogram, as shown in Figure 1.

Microneurography provides direct and beat-to-beat measurement of central sympathetic outflow to skeletal muscle or cutaneous circulation. Muscle sympathetic nerve activity recordings have a reliable intra-individual reproducibility over time, and nerve activity and pattern obtained from different sites in the same individual are very similar. ${ }^{5,6}$ The ability to quantitate muscle or skin nerve activity is also valuable.

However, microneurography only provides information regarding central sympathetic discharge to the regional vasculature innervated by the superficial nerve studied, but not to other regional vascular beds, such as renal or splanchnic circulation. This limits generalizability of SNA to the whole body due to regional variation in the control of SNA. ${ }^{1}$ Despite this major limitation, total body, cardiac, and renal norepinephrine spillover positively correlates with MSNA. ${ }^{7}$ Another limitation of microneurography is that burst amplitude is highly dependent on the position of the recording electrode relative to the active nerve fibers, making comparison of burst amplitude between different individuals problematic. ${ }^{5}$ Microneurography also provides information on the muscle or skin nerve activity under laboratory conditions with no information on ambulatory conditions. However, microneurography can be performed repeatedly in the same human subjects over long-term duration of months or years, which allows assessment of pharmacologic or non-pharmacologic intervention of the SNS.

\section{Plasma Norepinephrine Measurement}

Norepinephrine is the sympathetic postganglionic neurotransmitter, and measurement of this hormone has been used as a surrogate for SNA. Plasma NE is easy to obtain but has significant limitations.

Plasma NE concentration depends on the rate of release of the neurotransmitter from sympathetic nerves as well as mechanisms related to neurotransmitter clearance from plasma. ${ }^{8}$ Plasma NE concentration may be elevated in the conditions associated with decreased NE reuptake in the postsynaptic sympathetic nerve terminals, such as the use of cocaine or tricyclic antidepressants, or reduced renal clearance in the presence of renal failure, which is independent of central sympathetic outflow. ${ }^{9-11}$ Thus, without accounting for these factors, plasma NE serves as a poor marker for SNA. Furthermore, plasma NE represents a small fraction of the total NE released from neurotransmitter terminals and does not take into account the regional variation of SNS regulation. ${ }^{1}$ Finally, plasma NE concentration demonstrates suboptimal reproducibility, though this can be improved by obtaining the average of multiple repeated measurements in the supine position through a venous catheter that has been placed for at least 30 minutes. $^{5}$

\section{Norepinephrine Spillover}

Steady-state infusion of small amounts of tritiated NE permits the calculation of NE plasma clearance and NE spillover rate. This method addresses some of the limitations of plasma NE concentration because it accounts for NE clearance and has the ability to measure total body and organ-specific NE spillover using the following equations;

$$
\begin{aligned}
& \text { Organ NE spillover rate }=\left[\left(\mathrm{NE}_{\text {venous }}-\mathrm{NE}_{\text {arterial }}\right)+\right.\left.\left(\mathrm{NE}_{\text {arterial }}{ }^{*} \mathrm{~T}-\mathrm{NE} \mathrm{extraction}\right)\right] \times \mathrm{PF} \\
& \text { Total body NE spillover }=\frac{\text { Infusion rate of } \mathrm{T}-\mathrm{NE}(\mathrm{dpm})}{\text { Plasma NE specific activity }(\mathrm{dpm} / \mathrm{pg})} \\
& \text { Total body NE clearance }=\frac{\text { Infusion rate of T-NE }}{\text { Plasma T-NE concentration }}
\end{aligned}
$$

where $\mathrm{NE}_{\text {venous }}$ and $\mathrm{NE}_{\text {arterial }}$ are plasma venous and arterial norepinephrine concentrations respectively, $\mathrm{T}-\mathrm{NE}_{\text {extraction }}$ is the fractional extraction of tritiated norepinephrine across the organ, PF is organ plasma flow, $\mathrm{dpm}$ is disintegrations per minute of T-NE, and pg is picograms. ${ }^{12}$

Norepinephrine spillover does not directly measure NE release; thus it does not directly measure SNA. The rate of NE spillover is dependent on factors, such as reuptake at nerve terminals and into non-neural cells, o-methylation after reuptake into non-neural cells, and diffusion into plasma. Changes in these factors may affect conclusions drawn from this NE spillover test. Measurement of organ NE spillover requires simultaneous arterial 
and venous cannulation and infusion of radiolabeled NE. Thus, it is used mainly in the research setting and not applicable in clinical practice. Alteration in NE spillover in each organ may vary depending on the condition studied. For example, renal NE spillover is elevated in obese when compared to lean individuals. In contrast, cardiac NE spillover is paradoxically suppressed in obese when compared to lean individuals while the splanchnic NE spillover was comparable in lean and obese subjects. Thus, the regional NE spillover in one organ cannot be extrapolated to other organs or to the whole body response. ${ }^{13}$

\section{Neuroimaging}

Sympathetic activity has been investigated by neuroimaging techniques that use radiolabeled sympathetic amines (e.g., $\left[{ }^{123} \mathrm{I}\right]$ metaiodobenzylguanidine $/{ }^{123} \mathrm{I}-\mathrm{MIBG}$, $6\left[{ }^{18} \mathrm{~F}\right]$ fluorodopamine, $\left[{ }^{11} \mathrm{C}\right]$ - hydroxyephedrine) to image sympathetic innervation of an organ. The heart has been the most studied organ using sympathetic imaging and ${ }^{123} \mathrm{I}-\mathrm{MIBG}$ is the most utilized tracer. Washout of the injected $^{123} \mathrm{I}-\mathrm{MIBG}$ or heart:mediastinum ratio of MIBG radioactivity are used as a surrogate for cardiac sympathetic activity. ${ }^{5,14}$ Imaging techniques are limited by the costs and limited availability. Furthermore, certain drugs including cocaine, antidepressants, some antipsychotic drugs, and reserpine were shown to interfere with MIBG uptake, thereby limiting its sensitivity and specificity. ${ }^{15}$

\section{Heart Rate and Heart Rate Spectral Analysis}

Elevation in heart rate could be the consequence of sympathetic activation or vagal withdrawal. ${ }^{16}$ Power spectral analysis of heart rate variability was thought to provide more specific information regarding vagal vs sympathetic control of the heart rate. A power spectrum of very low $(\sim 0.03 \mathrm{~Hz})$, low $(\sim 0.05-0.15 \mathrm{~Hz})$, and high $(\sim 0.3-0.4 \mathrm{~Hz})$ frequency oscillations is constructed by Fourier transformation of instantaneous heart rate (converted from ECG-derived RR intervals). ${ }^{17}$ The area under the low-frequency (LF) oscillation was thought to represent cardiac sympathetic activity while the area under the high-frequency (HF) oscillation represents parasympathetic activity. However, this dichotomy has been called into question ${ }^{18}$ as autonomic blocking studies showed that the HF power was also increased by beta adrenergic receptor (AR) blocker propranolol and reduced by intranasal cocaine, which was not shown to have an impact on the vagal tone in humans. ${ }^{19,20}$ Furthermore, results from multiple studies have shown that LF spectral oscillations were not a measure of cardiac sympathetic activity, but rather a measure of baroreflex function. $^{18}$

\section{SYMPATHETIC NERVE ACTIVITY AND HYPERTENSION}

Using the technique of microneurography and other complementary techniques, researchers have observed sympathetic overactivity in pre-hypertensive individuals, suggesting the role of SNS in the pathogenesis of hypertension. ${ }^{21}$ Individuals with essential hypertension display high sympathetic nerve traffic when compared to normal controls across young, middle, and elderly age groups. ${ }^{1}$ Plasma NE, cardiac, and renal NE spillover were also shown to be elevated in hypertensive individuals compared to age-matched controls.,10,22 Sympathetic nerve activity as measured by microneurography is also increased in secondary forms of hypertension, including primary aldosteronism and renovascular hypertension, which was reversed after specific treatment to eliminate secondary causes (adrenalectomy for unilateral aldosterone producing adenoma and percutaneous renal intervention in renovascular hypertension). ${ }^{23,24}$ Total body NE spillover was also increased in patients with renovascular hypertension compared to age-matched controls. ${ }^{25}$ Sympathetic nerve activity and BP also increased in individuals with renal failure, which improved after renal transplantation, suggesting the role of renal disease in inducing sympathetic overactivation. ${ }^{26-28}$ Sympathetic innervation to the kidneys is potentially more important than SNS influence to other organs in BP regulation via increasing renal sodium absorption in the renal tubules via alpha $A R$, renin release through beta $A R$, and renal vasoconstriction through alpha AR mechanism. As a result, renal sympathetic denervation has been developed to reduce BP in patients with resistant hypertension. The procedures were designed to ablate both efferent nerve terminals and afferent nerve ending, which may, in turn, reduce overall central sympathetic discharge to other organs. However, recent studies failed to show reduction in $\mathrm{MSNA}^{29,30}$ as assessed by microneurography or cardiac sympathetic activity measured by ${ }^{123}$ I-MIBG after renal denervation. ${ }^{31}$

In addition to renal disease, previous studies have demonstrated increased SNA in individuals with type 2 diabetes mellitus, related to the sympathoexcitatory effects of insulin. Diabetic patients with hypertension display higher MSNA compared with hypertensive patients without diabetes. ${ }^{32}$ Similarly, higher levels of SNA have been observed in patients with both metabolic syndrome and hypertension when compared to patients with hypertension alone without metabolic syndrome. ${ }^{33}$ Individuals with obstructive sleep apnea (OSA) exhibit increased $\mathrm{SNA}^{34}$ related to chronic intermittent hypoxia causing activation of chemoreflex. Human studies have also demonstrated a strong association between OSA and hypertension, with a recent study showing a 
direct correlation between OSA severity and increase in MSNA in normotensive individuals. ${ }^{35,36}$ Functional brain imaging studies have shown that compared to controls, individuals with OSA have decreased signal intensity changes and increased gray matter concentration in brainstem regions important for SNA regulation, such as the rostral ventrolateral medulla, ventral mid-brain, dorsolateral pons, and medullary raphe. Furthermore, these changes were not only directly correlated with increase in MSNA but were reversed with chronic continuous positive airway pressure (CPAP) treatment with sustained improvement of mid-brain functional magnetic resonance imaging (fMRI) changes and SNA at 12 months. ${ }^{37}$ Thus, chronic intermittent hypoxia in OSA may predispose to anatomic and functional changes resulting in increase in sympathetic outflow from the brainstem center which can be ameliorated with CPAP. This increase in SNA seen in OSA is likely to be important in the recognition of OSA as an important secondary cause of hypertension and an important cause of uncontrolled or resistant hypertension. ${ }^{38,39}$

Excessive activation of SNS is not only implicated in the pathogenesis of hypertension, but also in the pathogenesis of hypertensive target organ complications. Patients with left ventricular hypertrophy (LVH) possess higher levels of SNA compared to hypertensive patients without LVH. ${ }^{40,41}$ Increased SNS activity has been linked to increased mortality in patients with congestive heart failure, renal failure, stroke, and chronic obstructive pulmonary disease, ${ }^{42-45}$ which may explain increased cardiovascular events in hypertensive patients with LVH.

\section{CONCLUSION}

Different methods used in evaluating SNA have shown that SNA is increased in various types of human hypertension. There is currently no ideal method for obtaining an instantaneous snapshot of the complex systemic regional regulation of SNA. Microneurography and NE spillover are the most direct methods for assessing SNA, though these methods are not used beyond the investigational setting or in highly specialized centers. Given the regional regulation of the SNS and the limitations of the different methods of evaluating SNA, the use of complimentary methods may provide a more comprehensive assessment of SNA in humans.

\section{REFERENCES}

1. Grassi G, Mark A, Esler M. The sympathetic nervous system alterations in human hypertension. Circ Res 2015 Mar 13;116(6):976-990.

2. Kalil GZ, Haynes WG. Sympathetic nervous system in obesity-related hypertension: mechanisms and clinical implications. Hypertens Res 2012 Jan;35(1):4-16.
3. Vallbo AB, Hagbarth KE, Wallin BG. Microneurography: how the technique developed and its role in the investigation of the sympathetic nervous system. J Appl Physiol 2004 Apr;96(4):1262-1269.

4. White DW, Shoemaker JK, Raven PB. Methods and considerations for the analysis and standardization of assessing muscle sympathetic nerve activity in humans. Auton Neurosci 2015 Dec;193:12-21.

5. Grassi G, Esler M. How to assess sympathetic activity in humans. J Hypertens 1999 Jun;17(6):719-734.

6. Grassi G, Bolla G, Seravalle G, TurriC, Lanfranchi A, Mancia G. Comparison between reproducibility and sensitivity of muscle sympathetic nerve traffic and plasma noradrenaline in man. Clin Sci 1997 Mar;92(3):285-289.

7. Wallin BG, Esler M, Dorward P, Eisenhofer G, Ferrier C, Westerman R, Jennings G. Simultaneous measurements of cardiac noradrenaline spillover and sympathetic outflow to skeletal muscle in humans. J Physiol 1992;453:45-58.

8. DiBona GF. Sympathetic nervous system and hypertension. Hypertension 2013 Mar;61(3):556-560.

9. Hasking GJ, Esler MD, Jennings GL, Burton D, Johns JA, Korner PI. Norepinephrine spillover to plasma in patients with congestive heart failure: evidence of increased overall and cardiorenal sympathetic nervous activity. Circulation 1986 Apr;73(4):615-621.

10. Esler M, Jennings G, Lambert G, Meredith I, Horne M, Eisenhofer G. Overflow of catecholamine neurotransmitters to the circulation: source, fate, and functions. Physiol Rev 1990 Oct;70(4):963-985.

11. Tuncel M, Wang Z, Arbique D, Fadel PJ, Victor RG, Vongpatanasin W. Mechanism of the blood pressure raising effect of cocaine in humans. Circulation 2002 Mar 5;105(9):1054-1059.

12. Sudhir K, Elser MD, Jennings GL, Komesaroff PA. Estrogen supplementation decreases norepinephrine-induced vasoconstriction and total body norepinephrine spillover in perimenopausal women. Hypertension 1997 Dec;30(6):1538-1543.

13. Vaz M, Jennings G, Turner A, Cox H, Lambert G, Esler M. Regional sympathetic nervous activity and oxygen consumption in obese normotensive human subjects. Circulation 1997 Nov;96(10):3423-3429.

14. Goldstein DS. Sympathetic neuroimaging. Handb Clin Neurol 2013;117:365-370.

15. Stefanelli A, Treglia G, Bruno I, Rufini V, Giordano A. Pharmacological interference with 123i-metaiodobenzylguanidine: a limitation to developing cardiac innervation imaging in clinical practice? Eur Rev Med Pharmacol Sci 2013 May;17(10):1326-1333.

16. Shen MJ, Zipes DP. Role of the autonomic nervous system in modulating cardiac arrhythmias. Circ Res 2014 Mar 14;114(6):1004-1021.

17. Spiers JP, Silke B, McDermott U, Shanks RG, Harron DW. Time and frequency domain assessment of heart rate variability: a theoretical and clinical appreciation. Clin Auton Res 1993 Apr;3(2):145-158.

18. Goldstein DS, Bentho O, Park MY, Sharabi Y. Low-frequency power of heart rate variability is not a measure of cardiac sympathetic tone but may be a measure of modulation of cardiac autonomicoutflowsbybaroreflexes. Exp Physiol2011Dec;96(12): 1255-1261.

19. Vongpatanasin W, Mansour Y, Chavoshan B, Arbique D, Victor RG. Cocaine stimulates the human cardiovascular 
system via a central mechanism of action. Circulation 1999 Aug 3;100(5):497-502.

20. Taylor JA, Myers CW, Halliwill JR, Seidel H, Eckberg DL. Sympathetic restraint of respiratory sinus arrhythmia: Implications for vagal-cardiac tone assessment in humans. Am J Physiol Heart Circ Physiol 2001 Jun;280(6):H2804-H2814.

21. GrassiG,SeravalleG,BertinieriG, TurriC,Dell'Oro R,StellaML, Mancia G. Sympathetic and reflex alterations in systodiastolic and systolic hypertension of the elderly. J Hypertens 2000 May;18(5):587-593.

22. Petersson MJ, Rundqvist B, Johansson M, Eisenhofer G, Lambert G, Herlitz H, Jensen G, Friberg P. Increased cardiac sympathetic drive in renovascular hypertension. J Hypertens 2002 Jun;20(6):1181-1187.

23. Miyajima E, Yamada $Y$, Yoshida $Y$, Matsukawa T, Shionoiri $H$, Tochikubo O, Ishii M. Muscle sympathetic nerve activity in renovascular hypertension and primary aldosteronism. Hypertension 1991 Jun;17(6 Pt 2):1057-1062.

24. Kontak AC, Wang Z, Arbique D, Adams-Huet B, Auchus RJ Nesbitt SD, Victor RG, Vongpatanasin W. Reversible sympathetic overactivity in hypertensive patients with primary aldosteronism. J Clin Endocrinol Metab 2010 Oct;95(10):4756-4761.

25. Johansson M, Elam M, Rundqvist B, Eisenhofer G, Herlitz H, Lambert G, Friberg P. Increased sympathetic nerve activity in renovascular hypertension. Circulation 1999 May 18;99(19):2537-2542.

26. Converse RL Jr, Jacobsen TN, Toto RD, Jost CM, Cosentino F, Fouad-Tarazi F, Victor RG. Sympathetic overactivity in patients with chronic renal failure. N Engl J Med 1992 Dec 31;327(27):1912-1918.

27. Klein IH, Ligtenberg G, Neumann J, Oey PL, Koomans HA, Blankestijn PJ. Sympathetic nerve activity is inappropriately increased in chronic renal disease. J Am Soc Nephrol 2003 Dec;14(12):3239-3244.

28. Grassi G, Quarti-Trevano F, Seravalle G, Arenare F, Volpe M, Furiani S, Dell'Oro R, Mancia G. Early sympathetic activation in the initial clinical stages of chronic renal failure. Hypertension 2011 Apr;57(4):846-851.

29. TankJ,HeusserK,BrinkmannJ,SchmidtBM,MenneJ,BauersachsJ, Haller H, Diedrich A, Jordan J. Spike rate of multi-unit muscle sympathetic nerve fibers after catheter-based renal nerve ablation. J Am Soc Hypertens 2015 Oct;9(10):794-801.

30. Vink EE, Verloop WL, Siddiqi L, van Schelven LJ, Liam Oey P, Blankestijn PJ. The effect of percutaneous renal denervation on muscle sympathetic nerve activity in hypertensive patients. Int J Cardiol 2014 Sep;176(1):8-12.

31. van Brussel PM, Eeftinck Schattenkerk DW, Dobrowolski LC, de Winter RJ, Reekers JA, Verberne HJ, Vogt L, van den Born BJ. Effects of renal sympathetic denervation on cardiac sympathetic activity and function in patients with therapy resistant hypertension. Int J Cardiol 2016 Jan 1;202:609-614.

32. Huggett RJ, Scott EM, Gilbey SG, Stoker JB, Mackintosh AF, Mary DA. Impact of type 2 diabetes mellitus on sympathetic neural mechanisms in hypertension. Circulation 2003 Dec 23;108(25):3097-3101.
33. Huggett RJ, Burns J, Mackintosh AF, Mary DA. Sympathetic neural activation in nondiabetic metabolic syndrome and its further augmentation by hypertension. Hypertension 2004 Dec;44(6):847-852.

34. Narkiewicz K, van de Borne PJ, Montano N, Dyken ME, Phillips BG, Somers VK. Contribution of tonic chemoreflex activation to sympathetic activity and blood pressure in patients with obstructive sleep apnea. Circulation 1998 Mar 17;97(10):943-945.

35. Peppard PE, Young T, Palta M, Skatrud J. Prospective study of the association between sleep-disordered breathing and hypertension. N Engl J Med 2000 May 11;342(19):1378-1384.

36. Hamaoka T, Murai H, Kaneko S, Usui S, Okabe Y, Tokuhisa H, Kato T, Furusho H, Sugiyama Y, Nakatsumi Y, et al. Singleunit muscle sympathetic nerve activity reflects sleep apnea severity, especially in severe obstructive sleep apnea patients. Front Physiol 2016 Mar 2;7:66.

37. Henderson LA, Fatouleh RH, Lundblad LC, McKenzie DK, Macefield VG. Effects of 12 months continuous positive airway pressure on sympathetic activity related brainstem function and structure in obstructive sleep apnea. Front Neurosci 2016 Mar 10;10:90.

38. Pedrosa RP, Drager LF, Gonzaga CC, Sousa MG, de Paula LK, Amaro AC, Amodeo C, Bortolotto LA, Krieger EM, Bradley TD, et al. Obstructive sleep apnea: the most common secondary cause of hypertension associated with resistant hypertension. Hypertension 2011 Nov;58(5):811-817.

39. Shamsuzzaman AS, Gersh BJ, Somers VK. Obstructive sleep apnea: implications for cardiac and vascular disease. JAMA 2003 Oct 8;290(14):1906-1914.

40. Schlaich MP, Kaye DM, LambertE,SommervilleM,Socratous F, Esler MD. Relation between cardiac sympathetic activity and hypertensive left ventricular hypertrophy. Circulation 2003 Aug 5;108(5):560-565.

41. Burns J, Sivananthan MU, Ball SG, Mackintosh AF, Mary DA, Greenwood JP. Relationship between central sympathetic drive and magnetic resonance imaging-determined left ventricular mass in essential hypertension. Circulation 2007 Apr 17;115(15):1999-2005.

42. Barretto AC, Santos AC, Munhoz R, Rondon MU, Franco FG, Trombetta IC, Roveda F, de Matos LN, Braga AM, Middlekauff HR, et al. Increased muscle sympathetic nerve activity predicts mortality in heart failure patients. Int J Cardiol 2009 Jul 10;135(3):302-307.

43. Andreas S, Haarmann H, Klarner S, Hasenfuss G, Raupach T. Increased sympathetic nerve activity in copd is associated with morbidity and mortality. Lung 2014 Apr;192(2):235-241.

44. PenneEL, NeumannJ,Klein IH, Oey PL, Bots ML, Blankestijn PJ. Sympathetic hyperactivity and clinical outcome in chronic kidney disease patients during standard treatment. J Nephrol 2009 Mar-Apr;22(2):208-215.

45. Sander D, Winbeck K, Klingelhofer J, Etgen T, Conrad B. Prognostic relevance of pathological sympathetic activation after acute thromboembolic stroke. Neurology 2001 Sep 11;57(5):833-838. 